\begin{tabular}{|c|l|}
\hline Title & Structure of the carbon nanofil laments formed by liquid phase carbonization in porous anodic al umina template \\
\hline Author(s) & Habazaki, H.; Kiriu, M.; Hay ashi, M.; Konno, H. \\
\hline Citation & $\begin{array}{l}\text { Materials Chemistry and Physics, 105(2-3), 367-372 } \\
\text { https://doi.org/10.1016/.matchemphys.2007.04.074 }\end{array}$ \\
\hline Issue Date & $2007-10$-15 \\
\hline Doc URL & http://hdl.handle.net/2115/30228 \\
\hline Type & article (author version) \\
\hline File Information & MCP105-2-3.pdf \\
\hline
\end{tabular}

Instructions for use 


\section{Structure of the Carbon Nanofilaments Formed by Liquid Phase Carbonization in Porous Anodic Alumina Template}

H. Habazaki*, M. Kiriu, M. Hayashi, H. Konno

Graduate School of Engineering, Hokkaido University, N13-W8, Sapporo 060-8628, Japan

*Corresponding author. Tel \& Fax; +81 11706 6575. E-mail address: habazaki@eng.hokudai.ac.jp (H. Habazaki) 


\begin{abstract}
Platelet structure carbon nanofilaments of $\sim 30 \mathrm{~nm}$ in diameter have been prepared by heating a mixture of porous anodic alumina template and poly(vinyl)chloride powders in an argon atmosphere, and the change in their structure and morphology with heat treatment temperature, ranging from 600 to $2800^{\circ} \mathrm{C}$, has been examined using $\mathrm{XRD}$, scanning electron microscopy, transmission electron microscopy and nitrogen gas adsorption measurements. The diameter of the carbon nanofilaments formed does not change with heat treatment temperature, being in agreement with the pore diameter of the template, while their length is reduced with the temperature. The platelet-type orientation of graphene layers is evident even at $600^{\circ} \mathrm{C}$ with the layer structure further developing with increasing heat treatment temperature. The carbon nanofilaments formed at lower temperatures have micropores, while those formed at higher temperatures do not have porosity. Highly graphitized carbon nanofilaments have been obtained after heat treatment at $2800^{\circ} \mathrm{C}$, with another characteristic structural feature being presence of loops at the edge of graphene layers formed at $2800^{\circ} \mathrm{C}$.
\end{abstract}

Keywords: A. nanostructures, B. heat treatment, C. electron microscopy, D. crystal structure 


\section{Introduction}

Carbon nanofilaments, often also referred to as carbon nanofibers, have attracted much attention due to their unique chemical and physical properties as well as their potential widespread applications. Preparation of carbon nanofilaments with well controlled diameter as well as controlled orientation and crystallization degree is of technical great importance. There are basically three types of carbon nanofilaments: platelet, herringbone and tubular structures [1], although recently a new type of carbon nanofilaments, i.e., cup-stacked type, has also been reported [2-4]. Among a range of preparation methods of carbon nanofilaments, including arc discharge, laser abrasion and catalytic chemical vapor deposition techniques, a template carbonization technique has an advantage for the preparation of nanocarbons with well controlled size and morphology. Porous anodic alumina is a suitable template for the preparation of carbon nanofilaments. When chemical vapor deposition has been applied to deposit carbonaceous materials into the straight pores of porous alumina, multi-walled carbon nanotubes, whose outer diameter is in agreement with pore diameter of the template, are generally formed [5-17].

Recently, liquid phase carbonization in the pores of porous anodic alumina template has been demonstrated to forms platelet carbon nanofilaments. Jian et al. have used mesophase pitch as a carbon precursor [18], while some of the present authors have utilized poly(vinyl)chloride (PVC) and poly(vinyl)alcohol (PVA) [19], both of which form pitch-like liquefied intermediate during thermal decomposition of the polymers. The template materials play an important role on orientation of graphene layers in carbon nanofilaments. The use of metallic aluminum template with square tunnel pits of $1 \mu \mathrm{m}$ square as a template and PVC precursor results in the formation of carbon filaments with a concentric structure [19], and similar structure has been obtained from a carbon-lined porous alumina template and mesophase pitch precursor [20]. 
In order to get further insights into the development of highly oriented carbon nanofilaments by liquid phase carbonization using the porous alumina template, structural change in the carbon nanofilaments formed by this technique with heat treatment temperature has been examined in this study using X-ray diffraction (XRD), scanning electron microscopy (SEM), transmission electron microscopy (TEM) and nitrogen gas adsorption measurements. Since the platelet carbon nanofilaments have numbers of exposed graphene edge sites, the materials are of considerable interest as catalysts [21] and electrodes for lithium ion batteries [22]. In fact, the authors have found that the carbon nanofilaments prepared by this method reveals a high rate capability as an anode of lithium ion batteries [23]. Thus, the structural characterization of the carbon nanofilaments formed at several temperatures is also of great importance for such applications.

\section{Experimental}

The template was prepared by anodizing of 99.99\% pure aluminum foil of $0.1 \mathrm{~mm}$ thickness at $25 \mathrm{~V}$ in $0.3 \mathrm{~mol} \mathrm{dm}{ }^{-3}$ sulfuric acid electrolyte at $15^{\circ} \mathrm{C}$, followed by pore widening treatment in 5\% phosphoric acid at room temperature for $30 \mathrm{~min}$. To get relatively uniform pore diameter and less branched pore channels, two-step anodizing was carried out [24]; the porous films formed by anodizing for $1 \mathrm{~h}$ was once dissolved in a chromic acid-phosphoric acid solution at $80^{\circ} \mathrm{C}$, and again porous alumina films were formed under the same conditions.

A mixture of the porous alumina template and PVC powders (TK-500, Shin-Etsu Chemicals Co. Ltd.) was heated in a stream of high purity argon at $400 \mathrm{~K} \mathrm{~h}^{-1}$ to $300^{\circ} \mathrm{C}$, and then it was kept at this temperature for 30 min. Around this temperature, PVC decomposes to liquefied pitch-like intermediate, penetrating into pores of the template. Subsequently, it was heated up to $600^{\circ} \mathrm{C}$ and kept for $1 \mathrm{~h}$. Then, templates were dissolved in $10 \% \mathrm{NaOH}$ solution and the carbon nanofilaments formed were filtered. The nanofilaments were heat-treated at 
1000 and $1500^{\circ} \mathrm{C}$ for $1 \mathrm{~h}$ and $2800^{\circ} \mathrm{C}$ for $30 \mathrm{~min}$ in a stream of high purity argon.

Structures of the carbon nanofilaments heat-treated at several temperatures were examined by X-ray diffraction with $\mathrm{Cu} \mathrm{K} \alpha$ radiation (Rigaku RINT2000), and the crystallographic parameters of $\mathrm{d}_{002}$ and $\mathrm{Lc}(002)$ were calculated in accordance with the JSPS procedure [25]. Silicon powders were used as an internal standard. Further, their morphologies and structures were examined using scanning electron microscope (JEOL JSM-6500F) with electron acceleration voltage of $5 \mathrm{kV}$ and transmission electron microscopy (JEOL JEM2010) operated at $200 \mathrm{kV}$. Nitrogen gas adsorption/desorption isotherms were also obtained at $-196^{\circ} \mathrm{C}$ using Bel Japan, Belsorp Mini.

\section{Results}

Fig. 1 shows scanning electron micrographs of carbon nanofilaments heat-treated at several temperatures. It is evident the formation of carbon nanofilaments with high aspect ratio. The diameter of the carbon nanofilaments is about $30 \mathrm{~nm}$, which is in agreement with pore diameter of the template. The carbon nanofilaments heat-treated at 600 to $2800^{\circ} \mathrm{C}$ have a similar diameter, but those become shorter, from more than several micrometers to less than 1 micrometer, with increasing heat treatment temperature. This should be associated with the fracture of the nanofilaments. As shown in later TEM image, the carbon nanofilaments formed at $600^{\circ} \mathrm{C}$ contains hollow regions where the carbon wall is rather thin. Such hollow regions should be the sites of fracture during heat treatment.

X-ray diffraction pattern of the carbon nanofilaments formed at $600^{\circ} \mathrm{C}$ (Fig. 2) reveals a halo, suggesting low crystallinity of the material. With increasing heat treatment temperature, the carbon 002 line becomes intense and its peak width is reduced. The 004 line appears only after heat treatment at $2800^{\circ} \mathrm{C}$, but still weak and broad. Although PVC is a soft carbon precursor, the X-ray diffraction pattern of the carbon nanofilaments heat-treated at 
$2800^{\circ} \mathrm{C}$ is different from that of typical graphite. As shown in Fig. 2(b), the 002 line consists of two overlapped peaks, and the $d_{002}$ values for these two peaks are 0.340 and $0.336 \mathrm{~nm}$ with the corresponding $\operatorname{Lc}(002)$ values being 27 and $43 \mathrm{~nm}$, respectively (Table 1). Thus, the region with turbostratic structures is apparently present in the carbon nanofilaments heat-treated at $2800^{\circ} \mathrm{C}$ in addition to the region of high degree of graphitization. From Table 1 , the degree of graphitization increases with heat treatment temperature.

The specific surface area of the carbon nanofilaments (Fig. 3) decreases with an increase in heat treatment temperature up to $1500^{\circ} \mathrm{C}$, above which the surface area becomes almost constant $\left(\sim 70 \mathrm{~m}^{2} \mathrm{~g}^{-1}\right)$. Since the calculated specific surface area, assuming a density of $3.0 \mathrm{~g} \mathrm{~cm}^{-3}$, for a carbon nanofilament of $30 \mathrm{~nm}$ in diameter without any porosity is also about $70 \mathrm{~m}^{2} \mathrm{~g}^{-1}$, the carbon nanofilaments heat-treated at high temperatures should have less, if any, porous structure. In reality, the nitrogen adsorption/desorption isotherms of the carbon nanofilaments heat-treated at $2800^{\circ} \mathrm{C}$ is typical of non-porous materials (Fig. 4). Compared with this material, the carbon nanofilaments heat-treated at $600^{\circ} \mathrm{C}$ reveals adsorption of nitrogen at very low relative pressure of nitrogen, indicating the presence of micropores. Such micropores should contribute to the increased specific surface areas for the low temperature-treated materials.

Detailed structure of the carbon nanofilaments has been further examined by transmission electron microscopy. The transmission electron micrograph of the carbon nanofilaments formed at $600^{\circ} \mathrm{C}$ (Fig. 5(a)) depicts again the formation of carbon nanofilaments of approximately $30 \mathrm{~nm}$ in diameter with high aspect ratio. It is evident that there are circular regions with light appearance in the carbon nanofilaments. Such regions should be hollow, being probably formed by generation of gas during thermal decomposition of PVC. The high resolution image (Fig. 5(b)) reveals that numbers of short layers of carbon are present, being approximately normal to the filament axis. Such orientation is also evident 
from the selected area electron diffraction pattern, showing that diffuse arcs are present only to the direction of filament axis. During further heating to higher temperatures, such orientation is preserved, and stacking of graphene layers in the direction of the filament axis becomes more obvious with increasing temperature (Fig. 6). The carbon nanofilaments heat-treated up to $1500^{\circ} \mathrm{C}$ has a relatively smooth surface, which changes a ragged surface after heat treatment at $2800^{\circ} \mathrm{C}$ (Fig. $7(\mathrm{a})$ ). Such change is associated with the development of loops at the edge of graphene layers (Fig. 7(b)), which are not obvious at lower temperatures. All the loops consists of $4 \sim 5$ layers. Apart from the loops the rather straight lattice fringes developed throughout the carbon nanofilaments indicate the highly improved degree of graphitization at $2800^{\circ} \mathrm{C}$ compared with those at lower temperatures.

\section{Discussion}

\subsection{Formation of platelet carbon nanofilaments}

The present TEM observations of the carbon nanofilaments have confirmed the development of platelet structure even at temperature as low as $600^{\circ} \mathrm{C}$. In the pitch-like liquid formed during carbonization of PVC, it is believed that poly-aromatic compounds are developed [26]. Hurt et al. have examined interaction of liquid phase poly-aromatic compounds in pitch with various substrates at $325^{\circ} \mathrm{C}$, reporting that large poly-aromatic compounds prefer edge-on molecular orientation at the interface with many substrates including aluminum oxide [27]. Thus, it is likely that the development of platelet structure of carbon nanofilaments originates the edge-on interaction of poly-aromatic compounds in a liquid phase formed from PVC with pore wall of anodic alumina. During solidification and carbonization by further heating, the orientation is preserved to form finally well-developed platelet structure carbon nanofilaments. This is essentially similar to the carbon nanofilaments formed from mesophase pitch in porous alumina template [18, 20]. 
From TEM observations of the carbon nanofilaments formed at $600^{\circ} \mathrm{C}$, it is evident that there are spherical hollow regions with intervals of several hundreds nanometers. During heating PVC in an inert atmosphere, liquefied pitch-like intermediate forms at $\sim 300^{\circ} \mathrm{C}$, which penetrates into the pores of the porous template. Carbonization proceeds up to about $500^{\circ} \mathrm{C}[28]$, during which gaseous products, such as carbon monoxide, carbon dioxide and hydrogen chloride, are evolved. With increasing temperature viscosity of the liquefied intermediate might increase. As a consequence, gas should be trapped in the pore of the template, forming hollow regions in the carbon nanofilemants.

It should be worth mentioning that thermal decomposition of PVC above $200^{\circ} \mathrm{C}$ generates corrosive hydrogen chloride gas, and it is likely that aluminum oxide is etched by such an aggressive gas. However, the carbon nanofilaments formed at $600^{\circ} \mathrm{C}$ has rather smooth surface (Fig. 2) and the diameter corresponds to the original pore diameter of the template, implying no etching of the pore wall of the template during the process. Absence of water vapor during the thermal decomposition process of PVC might avoid the corrosive etching of alumina template by hydrogen chloride generated.

\subsection{Structure of carbon nanofilaments heat-treated at $2800^{\circ} \mathrm{C}$}

TEM observation of the carbon nanofilaments heat-treated at $2800^{\circ} \mathrm{C}$ depicts high degree of graphitization (Fig. 7(b)). Another interesting feature is the development of loops at the edge of graphene layers. Possibly associated with the presence of the loops, XRD pattern of the carbon nanofilaments heat-treated at $2800^{\circ} \mathrm{C}$ (Fig. 2) is different from that of typical graphite. The two-overlapped 002 peaks demonstrate the presence of a turbostratic stacking region in addition to a typical $\mathrm{AB}$ graphite stacking region. Asymmetric 10 and 11 peaks also support the presence of turbostratic carbon. Since XRD pattern of multi-walled carbon nanotubes resembles turbostratic graphite $[29,30]$, there is a possibility that the structure of 
the region with loop in the carbon nanofilaments is similar to multi-walled carbon nanotubes. Assuming that the loops provide the turbostratic X-ray diffraction pattern, the $\operatorname{Lc}(002)$ value, $27 \mathrm{~nm}$, corresponding to the d002 value of $0.340 \mathrm{~nm}$ is larger than the thickness of the loops (less than $2 \mathrm{~nm}$ ). The 002 line of the multi-walled carbon nanotubes is also sharp[29, 30], such that the calculated $\operatorname{Lc}(002)$ should be larger than the radius of the nanotubes. Thus, for the curved graphene layers, thickness of the layers cannot be estimated from the 002 line broadening, although Lc values are often used to estimate the size of graphite.

The development of loops at the edge of graphene layers has been also reported after high temperature heat treatment of the platelet, herringbone and cup-stacked carbon nanofilaments prepared by catalytic chemical vapor deposition[2, 31-34]. In these reports it is interpreted that the edges of neighboring graphene layers are connected with each other to reduce the high reactivity of edge atoms. Zheng et al. have found the increased spacing between graphene layers around the loop connecting neighboring graphene layers[31]. This has been explained to be caused by strain of the bent graphene layers. Yoon et al. have reported that catalytically grown carbon nanofilaments have common sub-structures of carbon nanorods, which consist of a carbon cluster of 8-10 graphene layers with unique diameters of about $2.5 \mathrm{~nm}$ and variable lengths in the range of $15-100 \mathrm{~nm}$. Graphitization at high temperatures closes the ends of carbon hexagons in carbon nanorods to form concentrically layered dome-like caps on the surface of carbon nanofilaments. Such sub-structure of carbon nanorods should be formed by deposition of carbon on faceted catalyst surface. The process used to prepare the carbon nanofilaments in this work is totally different from the catalytic chemical vapor deposition. Thus, sub-structures for the carbon nanofilaments formed by catalytic chemical vapor deposition and the present liquid phase carbonization might be different. The detailed structural characterization of the present carbon nanofilaments formed at $2800^{\circ} \mathrm{C}$, with the help of exfoliation technique, is now in progress. 


\section{Conclusions}

From a mixture of PVC powders and porous anodic alumina template with pore diameter of $\sim 30 \mathrm{~nm}$, carbon nanofilaments with platelet structure are developed even as low as $600^{\circ} \mathrm{C}$. The filament diameter is independent of heat treatment temperature up to $2800^{\circ} \mathrm{C}$ with their length shortening with increasing the temperature. Spherical hollow regions are present in the carbon nanofibers heat-treated at low temperatures, possibly formed by gas generated during thermal decomposition of PVC. The carbon nanofilaments heat-treated up to $1000^{\circ} \mathrm{C}$ have micropores, while those heat-treated at higher temperatures do not have porosity. The degree of graphitization increases with increasing heat treatment temperature. After heat treatment at $2800^{\circ} \mathrm{C}$, loops consisting mostly of 5 layers are developed at the edges of graphene layers. The detailed structure of the loops is a subject of future study.

\section{Acknowledgments}

Thanks are due to Professor Y. Kaburagi, Musashi Institute of Technology for the heat treatment of the carbon nanofilaments at $2800^{\circ} \mathrm{C}$. The present work was supported in part from the Ministry of Education, Culture, Sports, Science and Technology (Exploratory Research No. 16651053) and Tokuyama Science Foundation.

\section{References}

[1] N.M. Rodriguez, J. Mater. Res. 8 (1993) 3233.

[2] M. Endo, Y.A. Kim, T. Hayashi, T. Yanagisawa, H. Muramatsu, M. Ezaka, H. Terrones, M. Terrones, M.S. Dresselhaus, Carbon 41 (2003) 1941.

[3] T. Yanagisawa, T. Hayashi, Y.A. Kim, Y. Fukai, M. Endo, Mol. Cryst. Liq. Cryst. 387 (2002) 391. 
[4] M. Endo, Y.A. Kim, T. Hayashi, Y. Fukai, K. Oshida, M. Terrones, T. Yanagisawa, S. Higaki, M.S. Dresselhaus, Appl. Phys. Lett. 80 (2002) 1267.

[5] T. Kyotani, L.F. Tsai, A. Tomita, Chem. Mater. 8 (1996) 2109.

[6] J.C. Hulteen, H.X. Chen, C.K. Chambliss, C.R. Martin, Nanostruct. Mater. 9 (1997) 133.

[7] G. Che, B.B. Lakshmi, C.R. Martin, E.R. Fisher, R.S. Ruoff, Chem. Mater. 10 (1998) 260.

[8] Z.H. Yuan, H. Huang, L. Liu, S.S. Fan, Chem. Phys. Lett. 345 (2001) 39.

[9] J.S. Lee, G.H. Gu, H. Kim, K.S. Jeong, J. Bae, J.S. Suh, Chem. Mater. 13 (2001) 2387.

[10] S.H. Jeong, H.Y. Hwang, K.H. Lee, Y. Jeong, Appl. Phys. Lett. 78 (2001) 2052.

[11] W.C. Hu, D.W. Gong, Z. Chen, L.M. Yuan, K. Saito, C.A. Grimes, P. Kichambare, Appl. Phys. Lett. 79 (2001) 3083.

[12] J.S. Suh, K.S. Jeong, J.S. Lee, I.T. Han, Appl. Phys. Lett. 80 (2002) 2392.

[13] S.H. Jeong, O.J. Lee, K.H. Lee, S.H. Oh, C.G. Park, Chem. Mater. 14 (2002) 1859.

[14] E.J. Bae, W.B. Choi, K.S. Jeong, J.U. Chu, G.S. Park, S. Song, I.K. Yoo, Adv. Mater. 14 (2002) 277.

[15] H. Pan, H. Gao, S.H. Lim, Y.P. Feng, J. Lin, J. Nanosci. Nanotech. 4 (2004) 1014.

[16] S.H. Jeong, H.Y. Hwang, S.K. Hwang, K.H. Lee, Carbon 42 (2004) 2073.

[17] H. Pan, H. Gao, S.H. Lim, Y.P. Feng, J. Lin, J. Nanosci. Nanotech. 5 (2005) 277.

[18] K. Jian, H.-S. Shim, A. Schwartzman, G.P. Crawford, H. Hurt, Adv. Mater. 15 (2003) 164.

[19] H. Konno, S. Sato, H. Habazaki, M. Inagaki, Carbon 42 (2004) 2756.

[20] C. Chan, G. Crawford, Y.M. Gao, R. Hurt, K.Q. Jian, H. Li, B. Sheldon, M. Sousa, N. Yang, Carbon 43 (2005) 2431.

[21] E.S. Steigerwalt, G.A. Deluga, C.M. Lukehart, J. Phys. Chem. B 106 (2002) 760. 
[22] S.H. Yoon, C.W. Park, H.J. Yang, Y. Korai, I. Mochida, R.T.K. Baker, N.M. Rodriguez, Carbon 42 (2004) 21.

[23] M. Kiriu, M. Hayashi, H. Habazaki, H. Konno, Electrochem. Commun. to be submitted

[24] H. Masuda, K. Fukuda, Science 268 (1995) 1466.

[25] T.J. Committee, Tanso (1963) 25.

[26] D. Dollimore, G.R. Heal, Carbon 5 (1967) 65.

[27] R. Hurt, G. Krammer, G. Crawford, K. Jian, C. Rulison, Chem. Mater. 14 (2002) 4558.

[28] M. Inagaki, K. Fujita, Y. Takeuchi, K. Oshida, H. Iwata, H. Konno, Carbon 39 (2001) 921.

[29] X.L. Zhao, Y. Ando, Jpn. J. Appl. Phys. Part 137 (1998) 4846.

[30] Y. Saito, T. Yoshikawa, S. Bandow, M. Tomita, T. Hayashi, Phys. Rev. B 48 (1993) 1907.

[31] G.-B. Zheng, H. Sano, Y. Uchiyama, Carbon 41 (2003) 853.

[32] S.H. Yoon, S. Lim, S.H. Hong, W.M. Qiao, D.D. Whitehurst, I. Mochida, B. An, K. Yokogawa, Carbon 43 (2005) 1828.

[33] S.H. Yoon, S.Y. Lim, S.H. Hong, I. Mochida, B. An, K. Yokogawa, Carbon 42 (2004) 3087.

[34] S. Lim, S.H. Yoon, I. Mochida, J.H. Chi, J. Phys. Chem. B 108 (2004) 1533. 
Figure captions

Fig. 1 Scanning electron micrographs of the carbon nanofilaments formed at several temperatures.

Fig. 2 (a) X-ray diffraction patterns of the carbon nanofilaments heat-treated at several temperatures. (b) 002 line of the carbon nanofilaments heat-treated at $2800^{\circ} \mathrm{C}$.

Fig. 3 Change in BET specific surface area of the carbon nanofilaments with heat treatment temperature.

Fig. 4 Nitrogen adsorption-desorption isotherms, measured at $-196^{\circ} \mathrm{C}$, for the carbon nanofilaments heat-treated at 600 and $2800^{\circ} \mathrm{C}$.

Fig. 5 (a) Transmission electron micrograph of the carbon nanofilaments formed at $600 \mathrm{oC}$.

(b) High magnification image of (a) as well as a selected area electron diffraction pattern.

Fig. 6 Transmission electron micrographs of the carbon nanofilaments heat treated at (a) $1000^{\circ} \mathrm{C}$ and (b) $1500^{\circ} \mathrm{C}$.

Fig. 7 (a) Transmission electron micrograph of the carbon nanofilaments heat treated at $2800^{\circ} \mathrm{C}$. (b) High magnification image in the side surface region of a carbon nanofilament. 
Table 1 Results of XRD analysis of the carbon nanofilaments heat-treated at several temperatures.

\begin{tabular}{ccc}
\hline Heat Treatment Temperature $\left({ }^{\circ} \mathrm{C}\right)$ & $\mathrm{d}_{002} / \mathrm{nm}$ & Lc (002) (nm) \\
\hline 1000 & 0.348 & 4 \\
1500 & 0.346 & 5 \\
& & 27 \\
2800 & 0.340 & 43 \\
\hline
\end{tabular}



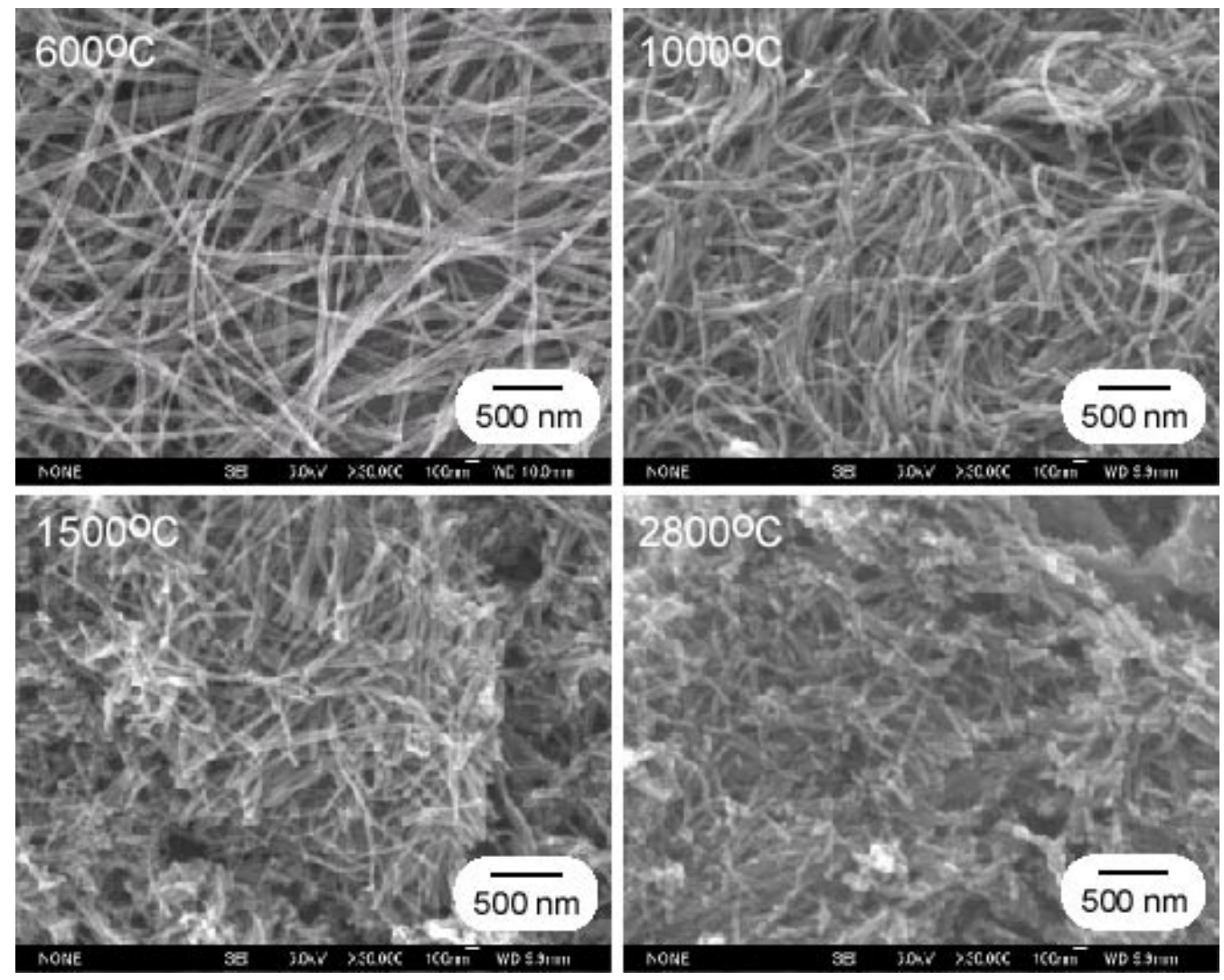

Fig. 1 Scanning electron micrographs of the carbon nanofilaments formed at several temperatures. 

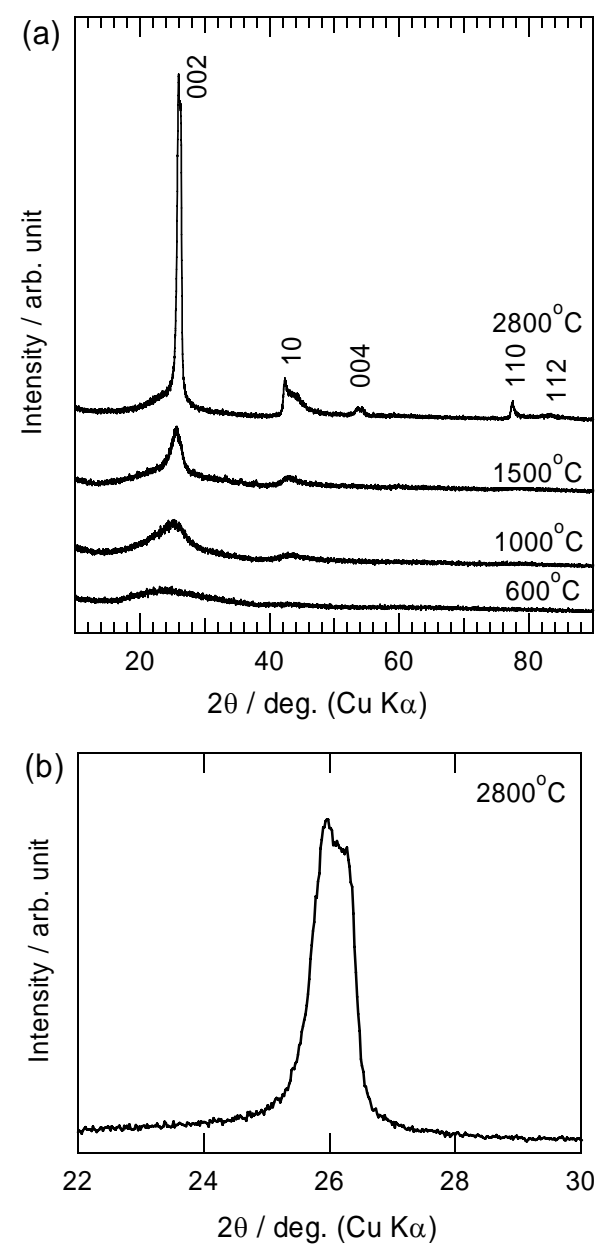

Fig. 2 (a) X-ray diffraction patterns of the carbon nanofilaments heat-treated at several temperatures. (b) 002 line of the carbon nanofilaments heat-treated at $2800^{\circ} \mathrm{C}$. 


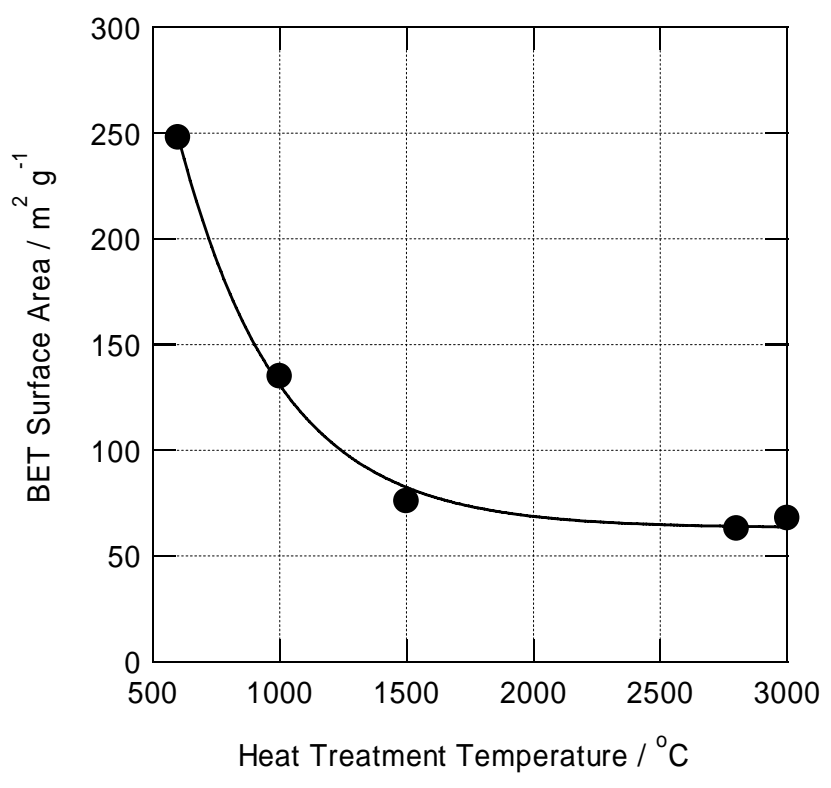

Fig. 3 Change in BET specific surface area of the carbon nanofilaments with heat treatment temperature. 


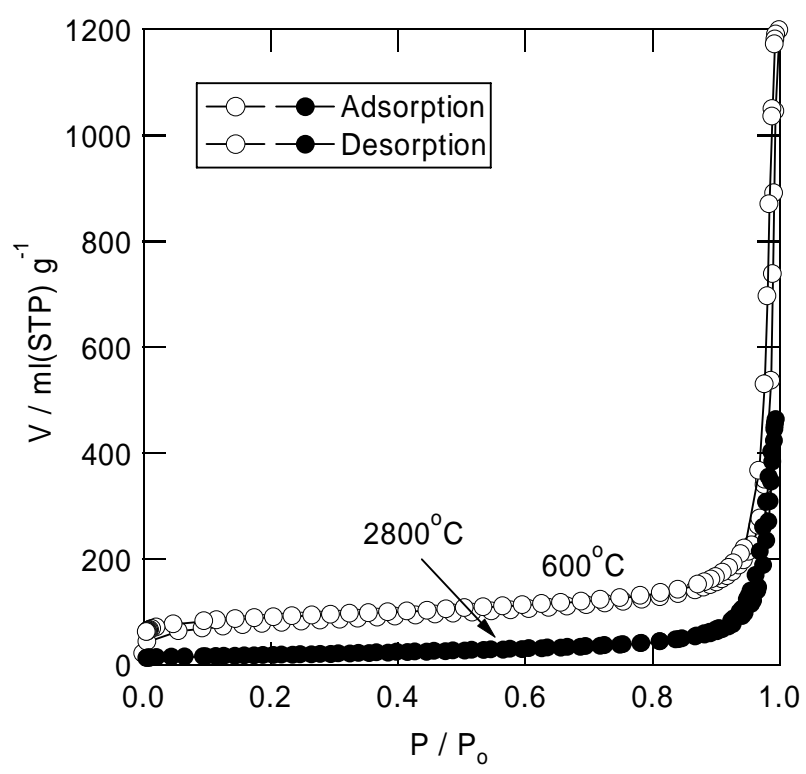

Fig. 4 Nitrogen adsorption-desorption isotherms, measured at $-196^{\circ} \mathrm{C}$, for the carbon nanofilaments heat-treated at 600 and $2800^{\circ} \mathrm{C}$. 
(a)

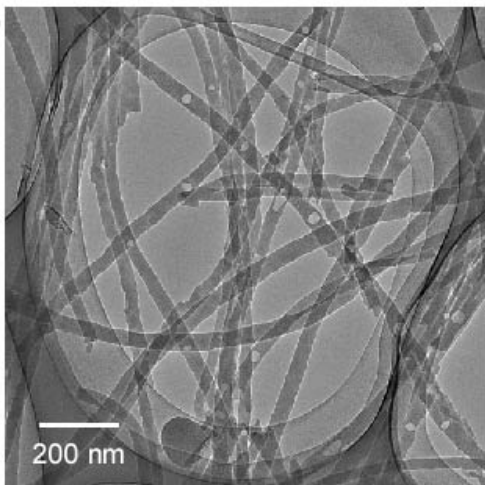

(b)

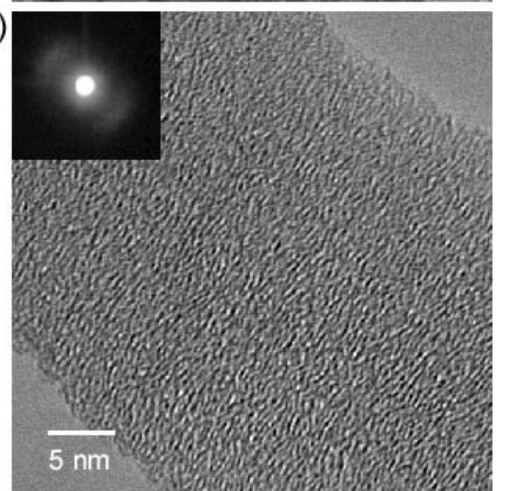

Fig. 5 (a) Transmission electron micrograph of the carbon nanofilaments formed at $600 \mathrm{oC}$.

(b) High magnification image of (a) as well as a selected area electron diffraction pattern. 


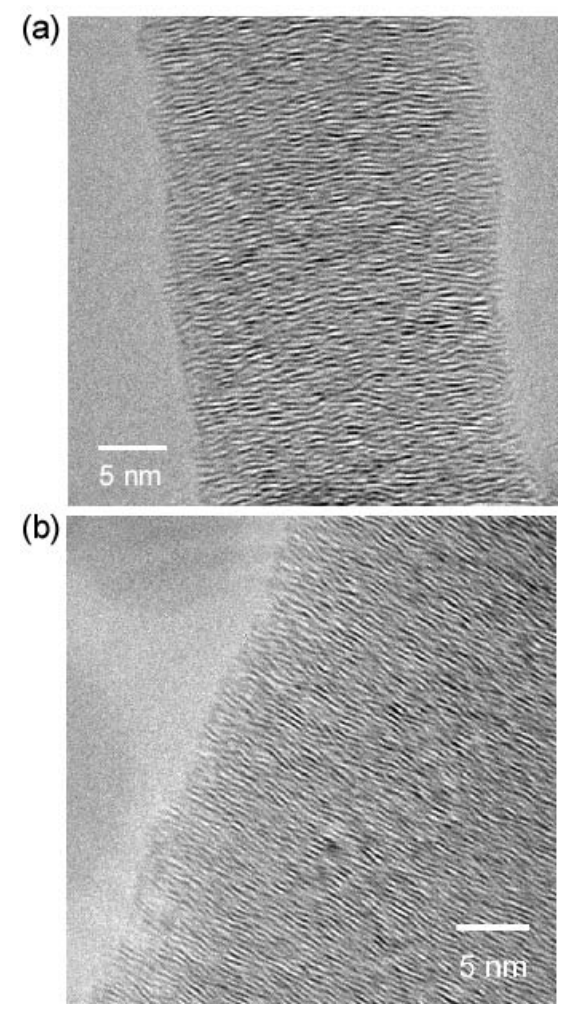

Fig. 6 Transmission electron micrographs of the carbon nanofilaments heat treated at (a) $1000^{\circ} \mathrm{C}$ and (b) $1500^{\circ} \mathrm{C}$. 
(a)

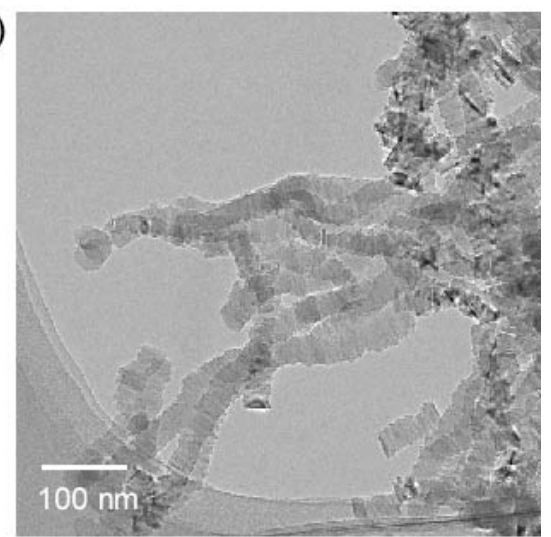

(b)

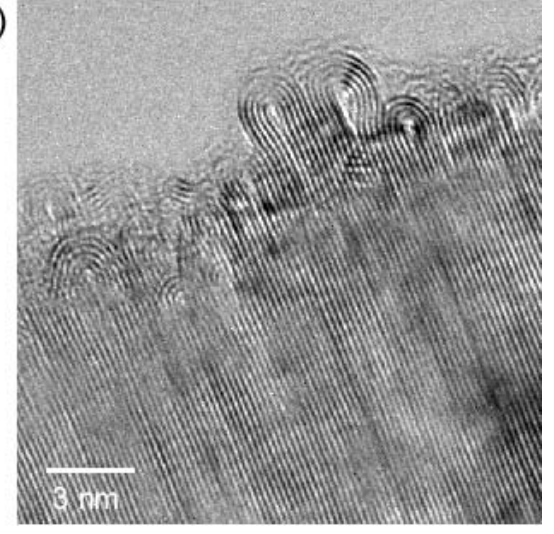

Fig. 7 (a) Transmission electron micrograph of the carbon nanofilaments heat treated at $2800^{\circ} \mathrm{C}$. (b) High magnification image in the side surface region of a carbon nanofilament. 